\title{
Simulation of Building Evacuation: Performance Analysis and Simplified Model
}

\author{
Yasser M. Alginahi \\ Dept. of Computer Science \\ Deanship of Academic Services \\ Taibah University, P.O. Box 344 \\ Madinah, Saudi Arabia
}

\author{
Muhammad N. Kabir \\ Faculty of Computer Systems and Software Engineering, \\ University Malaysia Pahang, \\ 26300 Gambang, \\ Pahang, Malaysia
}

\begin{abstract}
Crowd evacuation from industrial buildings, factories, theatres, protest areas, festivals, exhibitions and religious/sports gatherings is very crucial in many dangerous scenarios, such as fire, earthquakes, threat and attacks. Simulation of crowd evacuation is an integral part of planning for emergency situations and training staff for crow management. In this paper, simulation of crowd evacuation for a large building-hall is studied using a popular crowd-simulation software BuildingEXODUS. Evacuation of the fully occupied hall is simulated with eleven test cases using the different experimental setups in the software. The results of the different evacuation scenarios are analysed to check the effect of various parameters involved in the evacuation performance. Finally, using the evacuation test results, simplified models are developed. It is found that the model outputs are in good agreement with the simulation results. Therefore, the models can readily be used for fast computation of the evacuation results without running the actual simulation.
\end{abstract}

Keywords-Crowd Evacuation; BuildingEXODUS; Modelling \& Simulation; Least squares method

\section{INTRODUCTION}

The issue of crowd behaviour and movement has been a concern for researchers over the last few decades. Crowd evacuation from confined areas e.g., industry building, theatres, protest areas, festivals, exhibitions and religious/sports gatherings is utmost important in many dangerous events, such as fire, earthquakes, threat and attacks. Increasing the crowd density during the evacuation can lead to hazardous scenarios including crushing, being struck, violent acts, stampedes, etc. Simulation of crowd evacuation is integral part for planning to avoid such hazardous situations and to make efficient crowd management during the normal situation. Evacuation simulation is essential for designing (the number, widths and locations of) the exits of the confined area for safe evacuation of the occupants. Three approaches are used to simulate crowd, which are fluids, cellular automata and particles.

Most of the work in the area of crowd simulation uses the particle approach [1]. Many studies have been performed on crowd simulation with different structures and situations. A recent survey done by Wang and Sun [2] addresses the current research of large-scale crowd evacuation with four principal aspects: evacuation theories, evacuation modelling, evacuation decision-making and evacuation risk evaluation. The authors

This work is sponsored by the deanship of Scientific Research at Taibah University, Saudi Arabia. concluded that more research is required to be done on largescale evacuation since existing evacuation models have not fully considered the uncertain factors in the evacuation process. Thalmann et al [3] modelled virtual humans according to perception, emotion and behavior; Helbing et al. [4] produced a social force model for simulation of building escape panic; Braun et al. [5] modified the work of Helbing et al. by incorporating the concept of a group of pedestrians to the social force model. Bouvier et al. [6] simulated pedestrians and airbags deployment; and the work of Musse et al. [7] was based on decision-making and movement.

The work of Kiyona et al. [8] used the numerical analysis method, Distinct Element Method (DEM), to simulate emergency evacuation behaviour from a confined underground shopping center passageways during an earthquake. Chunmiao et al. [9] presented a study of evacuation process in buildings using BuildingExodus. They investigated the effect of number of exits and population and concluded that there was a linear relationship between the number of population and the evacuation time. Kiyono and Mori [10] considered an elliptic shape for human body to simulate emergency evacuation from a confined area. They used Distinct Element Method (DEM) with modified strength of the spring for high-density crowd to model the evacuation process and validated the model by comparing the simulation results with a real pedestrian flow.

Alighadr et al. [11] presented a case study on emergency evacuation of a populated marketplace called Timche Muzaffariyye using distinct element method DEM. They used two different numbers of exits for evacuation simulation in order to evaluate the performance. In addition, some research on guided evacuation techniques include: Onorati et al. [12] discussed modelling of accessible evacuation routes for different types of people, Yang et al. 2014 developed a modified social force model for pedestrian dynamics to better reflect pedestrians' behavioural characteristics. Abdelghany et al. [14] described an optimization model based on genetic algorithm for the evacuation of large-scale pedestrian facilities with multiple exit gates. Haron et al. [15] presents a study on fifty-five crowd simulation software and recommends the suitable crowd simulation software for studying crowd at large complexes. Alginahi et al. [1] presents a crowd simulation for the multi-storey washroom facilities using Discrete Event Simulation. Nassar and Bayyoumi, [16], which presents a discrete-event simulation model to assess the effect of mosque 
prayer hall configuration with different exit locations on the egress times of the occupants in the prayer hall.

From the above research works available in literature, it is very clear that crowd simulation research is an interesting area of research and much work is needed to address all different aspects and related parameters of crowd behaviour, building structures, characteristics of crowds, social behaviours etc.

In this work we simulate the crowd evacuation of a large building-hall considering different parameters involved in crowd simulation. The hall has eight doors each of which is approximately three meters in width. Figure 1 shows the layout of the hall used in this study. Three doors are located in the left side and five, in the right side of the figure. The dimension of the hall is approximately $87 \mathrm{~m} \times 58 \mathrm{~m}$, while each door is three meters wide. The purpose of simulating this building is to evaluate the evacuation performances with different test cases. Eleven tests cases generated by different experimental setups are simulated. Test results are analysed to scrutinize the influence of various parameters on the evacuation scenarios. Test results are analyzed to scrutinize the influence of various parameters on the evacuation performance. Furthermore, with the evacuation test results, simplified models are developed which are in excellent agreement with the test results. Therefore, instead of running the expensive simulation, one can readily use the simplified models for fast computation of the evacuation results.

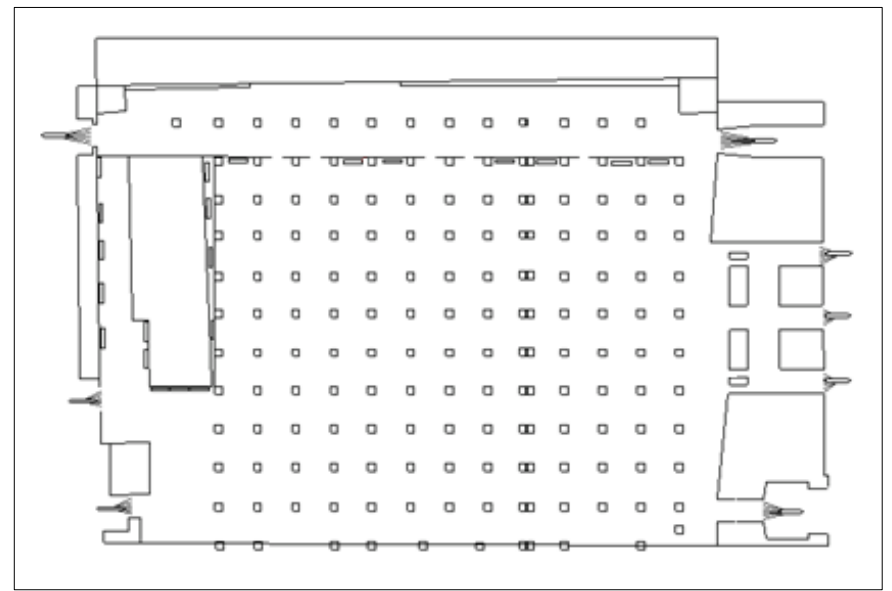

Fig. 1. Approximate layout for the Worshipping Hall (Area of study)

The rest of the paper is organized as follows. Following this introduction, section 2 provides the methodology and experimental setup. Section 3 presents the simulation results and analysis. The simplified evacuation model is formulated in section 4 and section 5 concludes this paper.

\section{Methodology AND EXPERIMENTAL SETUP}

The authors in this study decided to use BuildingEXODUS [17] in order to carry normal and emergency simulations for the large building-hall. The main reason for using
BuildingEXODUS is its popularity and affordable price. According to the crowd evacuation software evaluation by Haron et al., [15], BuildingEXODUS is considered one of the most popular crowd evacuation software developed at the University of Greenwich. BuildingEXODUS is a suite of software tools designed to simulate the evacuation and movement of people within complex structures. BuildingEXODUS is one of the evacuation models contained in this software package. BuildingEXODUS can be used to demonstrate compliance with building codes, evaluate the evacuation capabilities of all types of structures and investigate population movement efficiencies within structures. The system is able to simulate the evacuation of large number of people from different types of buildings such as multi-floor buildings. BuildingEXODUS adopts fluid dynamic models coupled with discrete virtual reality simulation techniques.

Eleven experiments (test cases) were conducted to evaluate the evacuation performances. The test cases with their description are provided in Table 1. The number of occupants in the hall is 4100 which is the estimated maximum capacity before the evacuation begins. Now the experimental setup of parameters, initial values and other considerations for simulation using BuildingEXODUS manual are discussed for each test case.

TABLE I. DESCRIPTION OF THE DIFFERENT EXPERIMENTAL SCENARIOS

\begin{tabular}{|c|c|}
\hline Case & Description \\
\hline 1 & Using default settings of BuildingEXODUS \\
\hline 2 & With altered potential map \\
\hline 3 & With full local familiarity \\
\hline 4 & With $50 \%$ attractiveness for all doors \\
\hline 5 & $\begin{array}{l}\text { With } 5 \% \text { of the population in wheelchairs and using travel speeds } \\
\text { as specified in the Exodus manual }\end{array}$ \\
\hline 6 & With response time (0-1 seconds) and potential map in test case 2 \\
\hline 7 & With response time (0-5 seconds) and potential map in test case 2 \\
\hline 8 & $\begin{array}{l}\text { With response time ( } 0-10 \text { seconds) and potential map in test case } \\
2\end{array}$ \\
\hline 9 & With extreme behavior enabled and potential map test case 2 \\
\hline 10 & Avoid congestion and potential map in test case 2 \\
\hline 11 & Combination of test cases $2,5,6,9$ and 10 \\
\hline
\end{tabular}

In test case 1 , default values as specified in the user manual are considered for objects i.e., doors, nodes, arcs and occupants with exception of ages of individuals. Occupants follow the potential map of the geometry given in Figure 2. Potential is a measure of a node distance from the nearest door. The occupants move from the nodes of higher potential to the nodes of lower potential which brings them closer to the nearest door. Occupants do not make decisions that take them to nodes of higher potential, but prefer to wait until an alternative of lower potential is offered. For this test case, the behaviour of the population is normal indicating that they conform to the potential map at all times and do not redirect unless they fall under the potential influence of a nearby exit [17]. 


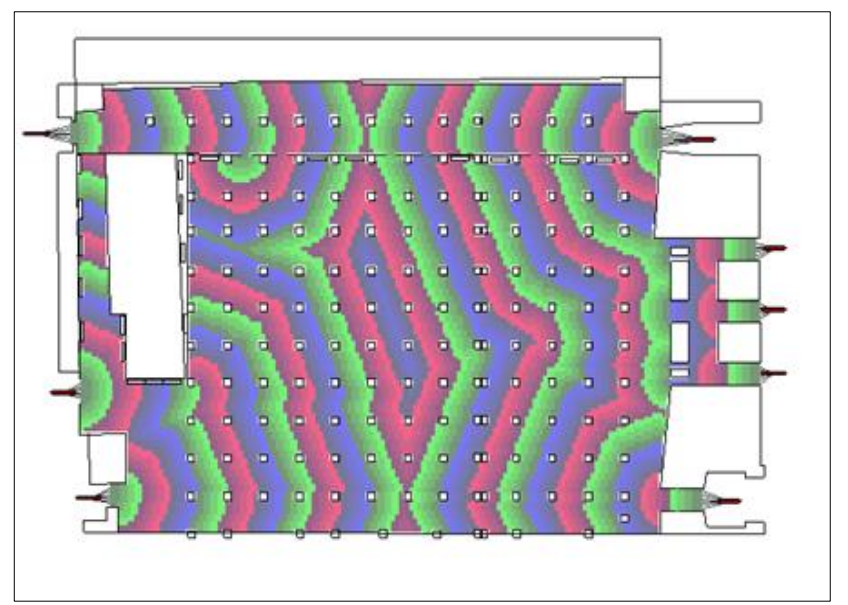

Fig. 2. Default potential map

In test case 2, internal exits are inserted with potential values as specified in Table 2. The corresponding potential map is displayed in Figure 3. In test case 3, the occupants do not follow the potential map. All the occupants are assumed to be familiar with all exits. Occupants behaviour is normal indicating that the occupant knowledge of exits is prioritized according to the initial distance of the exits from the occupant and usages of the doors.

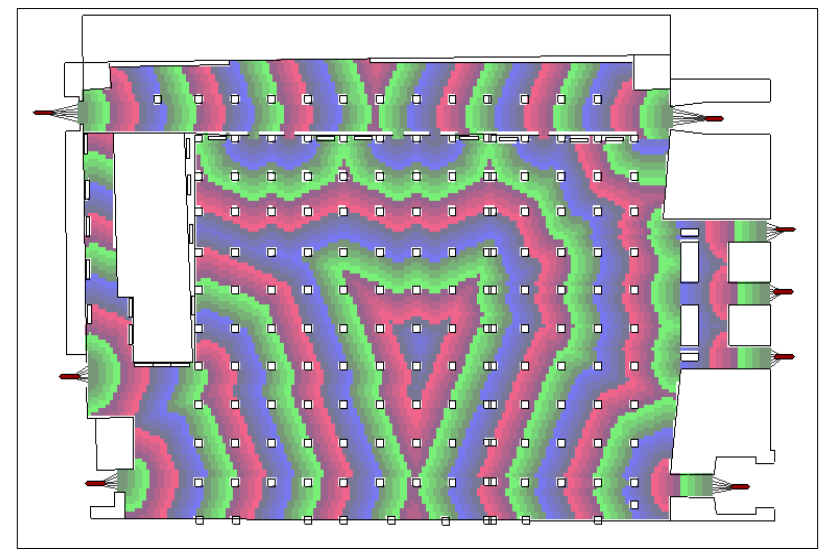

Fig. 3. Potential map for Test Case 2

TABLE II. InTERNAL EXITS with Potential VALUES

\begin{tabular}{|l|l|l|l|}
\hline Door No. & Potential & Door No. & Potential \\
\hline D1 & 100.000 & InDoor_1 & 100.000 \\
\hline D2 & 100.000 & InDoor_2 & 100.000 \\
\hline D3 & 100.000 & InDoor_3 & 100.000 \\
\hline D4 & 100.000 & InDoor_4 & 100.000 \\
\hline D5 & 100.000 & InDoor_5 & 100.000 \\
\hline D6 & 100.000 & InDoor_6 & 100.000 \\
\hline D7 & 100.000 & & \\
\hline D8 & 100.000 & & \\
\hline
\end{tabular}

Test case 4 is similar to the previous test case 3 with the exception that the occupants knowledge of a certain doors is automatically determined by a probability value supplied as the attractiveness of the door. We consider that for each door, $50 \%$ of the population are familiar with it (by probability). Occupants exit from one of the doors which they are familiar with. As in the previous case, the occupants exit list is ordered according to initial distance and the usage of the door. In test case 5, with wheelchairs and travel speeds according to the evacuation model data presented in Table 3.

TABLE III. TRAVEl SPEEDS FOR TEST CASE 5

\begin{tabular}{|l|l|l|l|}
\hline Panel & Age & Percentage & Speed (min-max) \\
\hline 1 & $3-16$ & 10 & $0.78-1.578$ \\
\hline 2 & $17-29$ & 25 & $1.586-1.49$ \\
\hline 3 & $30-55$ & 37.5 & $1.48-1.255$ \\
\hline 4 & $56-80$ & 22.5 & $1.246-1.03$ \\
\hline 5 (Wheel chair) & $30-80$ & 5 & 0.69 \\
\hline
\end{tabular}

Test cases 6-11 use the altered potential map of test case 2 given in Figure 3. Test cases 6-8 use different response time as shown in Table 1 . In test case 6 , response time ranges between zero and one second for the entire population. In test case 7 , response time is increased to be between zero and five seconds. Test case 8 has the maximum response time range i.e., between zero and ten seconds for the entire population.

Test case 9 uses extreme behaviour where the occupant movement only relies on the distance from the exits. In this case, the population moves according to the altered potential map. However, they are given the additional option of moving to locations of higher potential when their wait time exceeds their patience limit which ranges from 0-5 minutes. In test case 10, a sign was associated with each door enabling the occupants to observe the area around the door and assess the congestion around it .The occupants can then make the decision to avoid the congestion by redirecting to another door. The visibility catchment area of signs given in Figure 4 is the area which it is visible by the occupants. Only occupants within this area are able to view the sign and the congestion around it. Test case 11 is produced with the combination of test cases 2, 5, 6, 9 and 10 .

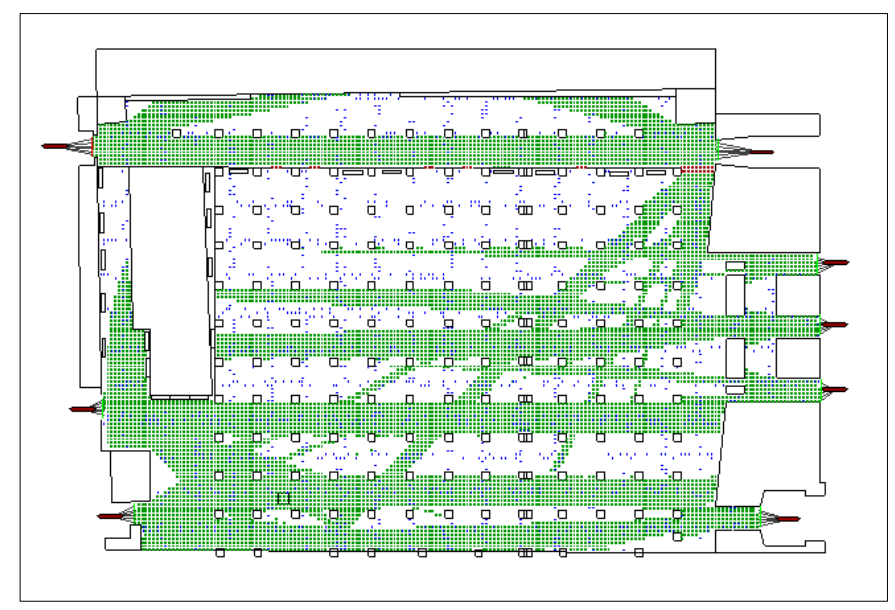

Fig. 4. Visibility catchment area of the signs

\section{RESULTS AND ANALYSIS}

The results of the test cases described in the previous section are explained and analysed. The complete graphical results from test case 1 are provided to demonstrate the capability of the software. The complete results of other test cases are provide in Tables $4-5$ for all test cases. However, results of all the test cases which are required for the comparison and analysis are presented. Figures 5-7 and 
Tables 4-5 present the results of test case 1 . Figures $5 a-5 b$ plots the flow rate of the people through D1 to D8 doors while Figure 5c displays the total flow rate from all the doors. It can be observed that the flow rate is initially zero and increases to some value (average maximum flow rate) and continues to fluctuate around the value before sharply reducing to zero. Note that the average maximum flow rate is about 16 for all 8 doors. The maximum flow rate in Figure $5 \mathrm{c}$ with all doors is about $128(16 \times 8=128)$. The evacuation time is the longest with door D8 that equalled 338 seconds; Table 5 verifies this.

Table 5 provides the total and average evacuation time for all the doors, average response time and average cumulative wait time, average distance and optimal performance statistics (OPS). Note that OPS is measured from 0.0 to 1.0, where the lower values indicate more efficient evacuation [17]. Table 4 shows the door usage i.e., how many evacuees exit through each door. Figure 6 shows the total number of evacuee over time for the doors corresponding to the doors in Figure 5. Note that the general trends of the total number of evacuee are almost linear with time i.e., increase gradually and then they become constant after the evacuation is over. Figure 7 shows the areas of congestion for test case 1 where the duration of congestion exceeds $10 \%$ of the evacuation time.

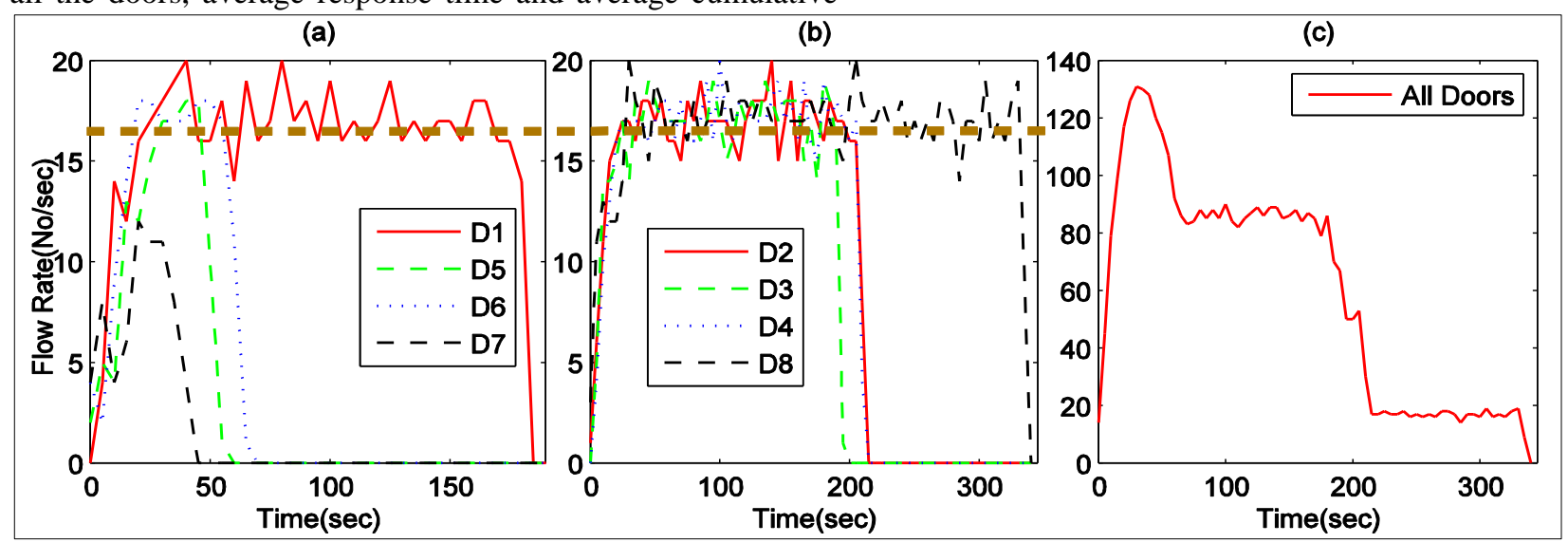

Fig. 5. Evacuation flow rate over time with different doors in test case 1

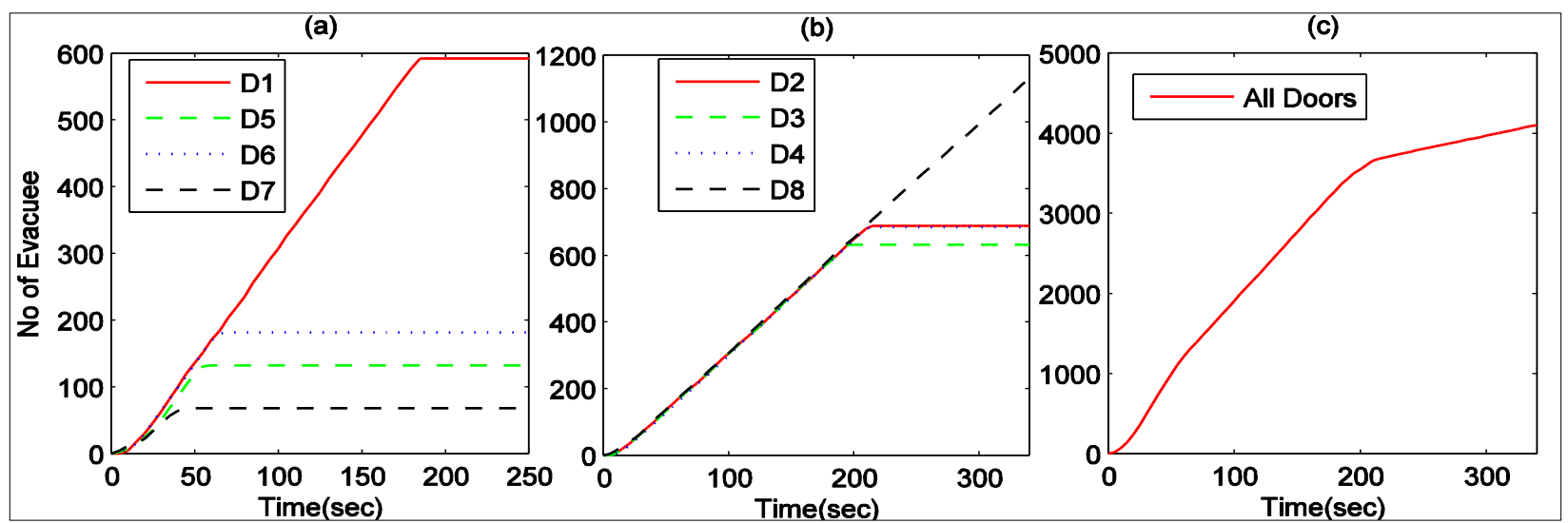

Fig. 6. Total number of evacuees over time with different doors in test case 1 


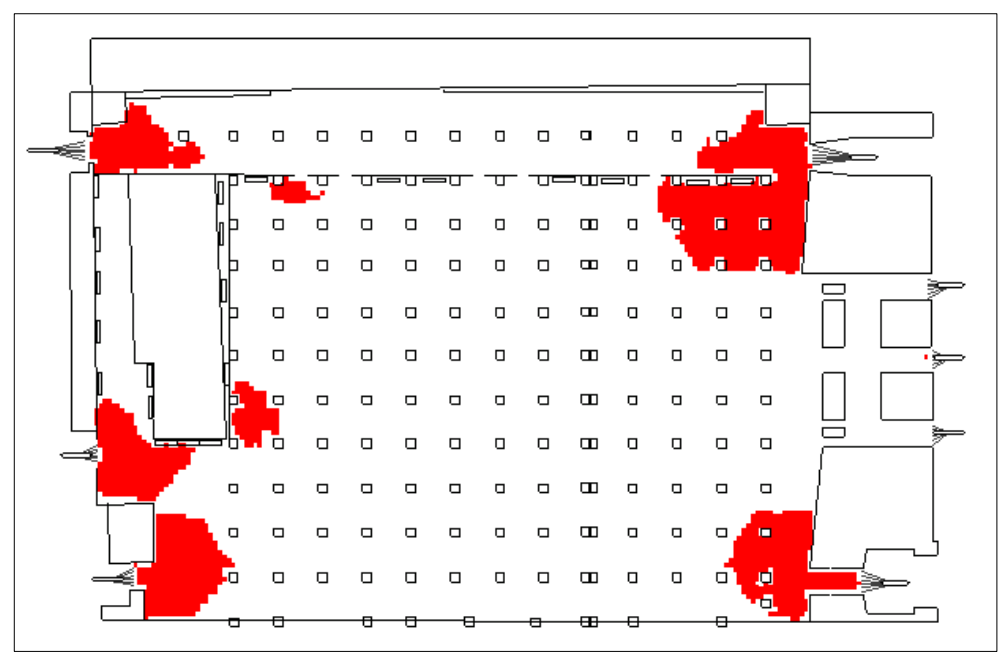

Fig. 7. Areas of congestion for test case 1

TABLE IV. Door Usage For All Test CASes

\begin{tabular}{|c|c|c|c|c|c|c|c|c|c|c|c|}
\hline \multirow{3}{*}{ Door No } & \multicolumn{11}{|c|}{ Test Cases } \\
\hline & 1 & 2 & 3 & 4 & 5 & 6 & 7 & 8 & 9 & 10 & 11 \\
\hline & \multicolumn{11}{|c|}{ No. of Evacuees } \\
\hline D1 & 1124 & 1004 & 1091 & 739 & 1001 & 983 & 1053 & 1051 & 1003 & 892 & 750 \\
\hline D2 & 132 & 151 & 155 & 362 & 136 & 125 & 135 & 139 & 152 & 247 & 360 \\
\hline D3 & 181 & 240 & 165 & 368 & 256 & 251 & 233 & 251 & 238 & 224 & 370 \\
\hline D4 & 68 & 157 & 73 & 348 & 141 & 150 & 144 & 136 & 160 & 293 & 361 \\
\hline D5 & 684 & 713 & 690 & 517 & 753 & 796 & 726 & 731 & 712 & 625 & 522 \\
\hline D6 & 631 & 638 & 602 & 605 & 616 & 599 & 561 & 611 & 601 & 727 & 599 \\
\hline D7 & 688 & 604 & 733 & 694 & 582 & 638 & 665 & 640 & 641 & 557 & 659 \\
\hline D8 & 592 & 593 & 591 & 467 & 615 & 558 & 583 & 541 & 593 & 535 & 479 \\
\hline
\end{tabular}

TABle V. Summary of Evacuation Estimates for All Test Cases with the Initial Population of 4100 Inside the Building

\begin{tabular}{|c|c|c|c|c|c|c|c|}
\hline \multirow{2}{*}{$\begin{array}{l}\text { Test } \\
\text { Cases }\end{array}$} & \multicolumn{2}{|c|}{ Total Elapsed Time } & \multirow{2}{*}{ OPS } & \multirow{2}{*}{$\begin{array}{l}\text { Average Total } \\
\text { Elapsed Time (Sec) }\end{array}$} & \multirow{2}{*}{$\begin{array}{l}\text { Average } \\
\text { Response } \\
\text { Time (Sec) } \\
\end{array}$} & \multirow{2}{*}{$\begin{array}{l}\text { Average } \\
\text { Cumulative Wait } \\
\text { Time (Sec) }\end{array}$} & \multirow{2}{*}{$\begin{array}{l}\text { Average } \\
\text { Distance }\end{array}$} \\
\hline & Sec & Min & & & & & \\
\hline 1 & 338.25 & 5.6375 & 0.591 & 117.92 & 14.90 & 77.87 & 31.68 \\
\hline 2 & 300.07 & 5.00117 & 0.525 & 107.83 & 15.16 & 65.95 & 33.35 \\
\hline 3 & 329.47 & 5.49117 & 0.575 & 116.40 & 15.16 & 75.76 & 31.67 \\
\hline 4 & 232.32 & 3.872 & 0.230 & 98.51 & 15.16 & 49.70 & 41.03 \\
\hline 5 & 301.09 & 5.018 & 0.513 & 110.30 & 14.99 & 66.61 & 33.64 \\
\hline 6 & 305.49 & 5.0915 & 0.491 & 116.15 & 29.66 & 60.19 & 32.73 \\
\hline 7 & 352.74 & 5.879 & 0.078 & 177.59 & 149.07 & 5.02 & 29.09 \\
\hline 8 & 642.29 & 10.7048 & 0.032 & 323.16 & 297.95 & 2.06 & 28.58 \\
\hline 9 & 304.92 & 5.082 & 0.534 & 107.90 & 15.16 & 61.27 & 39.65 \\
\hline 10 & 273.75 & 4.562 & 0.362 & 101.42 & 14.99 & 57.15 & 35.99 \\
\hline 11 & 390.62 & 6.51 & 0.065 & 187.39 & 152.34 & 2.47 & 38.50 \\
\hline
\end{tabular}

Figure 8 shows the total and average elapsed (evacuation) time for all doors, average response time, average cumulative wait time and the average distance for the different test cases. Figure 9 shows a bar graph depicting the optimal performance statistics (OPS) for the test cases. We observe that the average evacuation time follows the trend of total evacuation time. The evacuation time is the minimum with test case 4 and highest with test case 8 . Average wait time mostly makes the opposite behaviour of evacuation time. OPS follows the similar behaviour of average wait time. It reveals that if the response time increases, the evacuation time and response time increase, but the wait time and the OPS decrease. Test cases 4 and 10 have the smallest evacuation time since case 4 uses $50 \%$ attractiveness for all doors and test case 10 uses sign to 
signal the occupants of the congestion. However, wait time for test case 10 is higher than that of test case 4 . Test case 5 where some $5 \%$ occupants use wheelchairs does not make much difference with the default setting or altered potential map in test case 2 . The same behaviour is also observed with test case 9 which represents the extreme behaviour. Variation of average distance is very small for different cases.

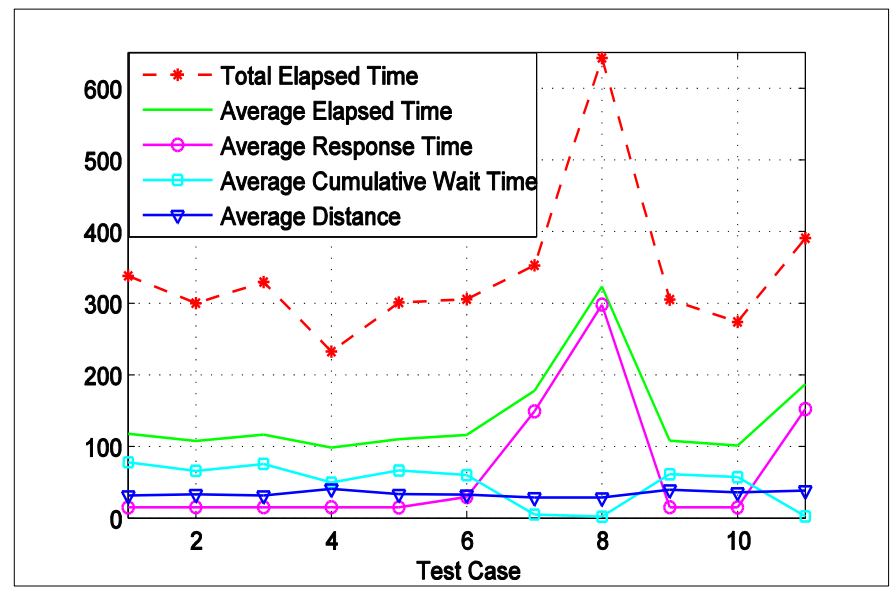

Fig. 8. Evacuation estimates with different test cases

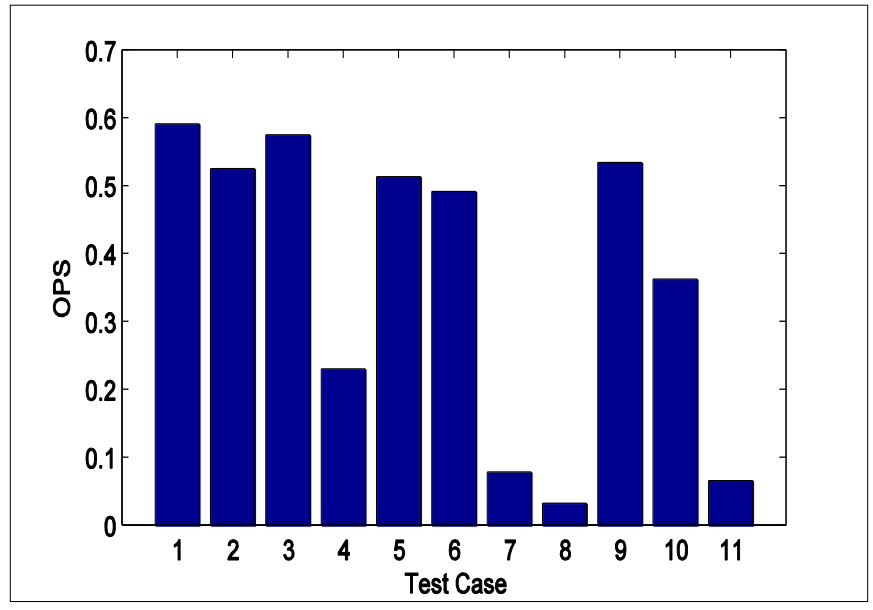

Fig. 9. Optimal Performance Statistics for all test cases

\section{SIMPlifiEd EVACUATION MOdEL}

The evacuation results through all the doors presents wellbehaved trajectories without any fluctuation. Therefore, the trajectories can be fitted with some functions so that the result can be readily obtained from the functions without running the simulation repeatedly. Besides the computational time is much cheaper for the evacuation if we can build such functions.
First, we try to find the different evacuation patterns. In Figure 10, the number of evacuees through all the doors is plotted over time for different test cases. It is observed that in the figure, the plots with almost identical behaviours are grouped. It is apparent in Figure 10 (a) that the evacuation behaviours with the test cases $1,2,3,5,6$ are similar. This similarity can also be observed for test cases 4 and 9; and 7 and 11 as shown in Figures 10 (b) and 10 (c) respectively Notice that the evacuation with the test case 8 is different from the others. The average number of evacuees over time for the test cases with similar evacuation behaviour is referred to as the evacuation pattern. These evacuation patterns are plotted in Figure 11. The goal here is fit the evacuation pattern by a model function.

The Matlab cftool is used to find the most appropriate functions to fit the evacuation patterns. Figure 11 plots the number of evacuee over time and their fitting functions for different evacuation patterns. Each plot can be identified by different line properties presented in the legends. Different types of functions were tried to fit these data. Finally, the function produces the best fit was chosen and was used for the plots in Figure 11

The function is presented as follows

$$
f(t)=p_{0}+p_{1} t+p_{2} t^{2}+p_{3} t^{3}+\cdots+p_{6} t^{6}
$$

Equation (1) which is a function of order 6. This function is used for fitting the simulation data of number of people over time t. The fitting is performed using least squares method which generates the values of $p_{0}, p_{1}, \ldots p_{6}$. Once these values are determined, the plot of number of people over time can be accomplished. The values of $p_{0}, p_{1}, \ldots p_{6}$ obtained from the least squares method are listed in Table 6 below. Table 6 provides the values and root mean square error (RMSE) values of $\mathrm{f}(\mathrm{t})$ for different evacuation patterns. The values of $p_{0}, p_{1}, \ldots p_{6}$ are different for different patterns due to their different evacuation data. For a specific pattern, the values will be constant. Thus using these constants, the function $\mathrm{f}(\mathrm{t})$ can be used for evaluating associated output for any value of time t. The last row in Table 6 provides RMSE with which errors with the data fitting can be readily checked i.e., how closely the function fits with the data. Since the simulation uses assumptions and approximations, the functions can never fit perfectly with the simulation results. As mentioned earlier, that we tried a number of functions to fit with the data and the best and most reasonable function given in equation (1) was considered for fitting the data. Figure 11 demonstrates how closely the function fits the data. We observe that the function and the data are in a good agreement. Hence, it can be concluded that the functions can be used to evaluate the associated values. 


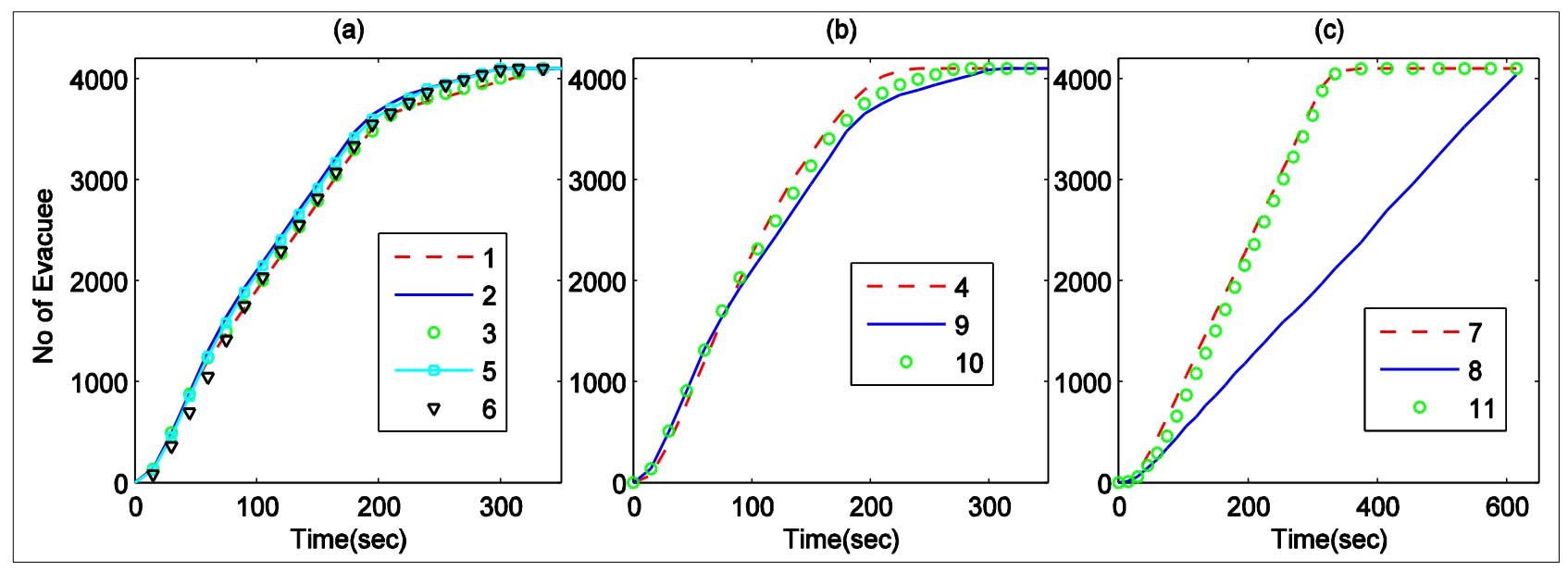

Fig. 10. Evacuation with time for different test cases

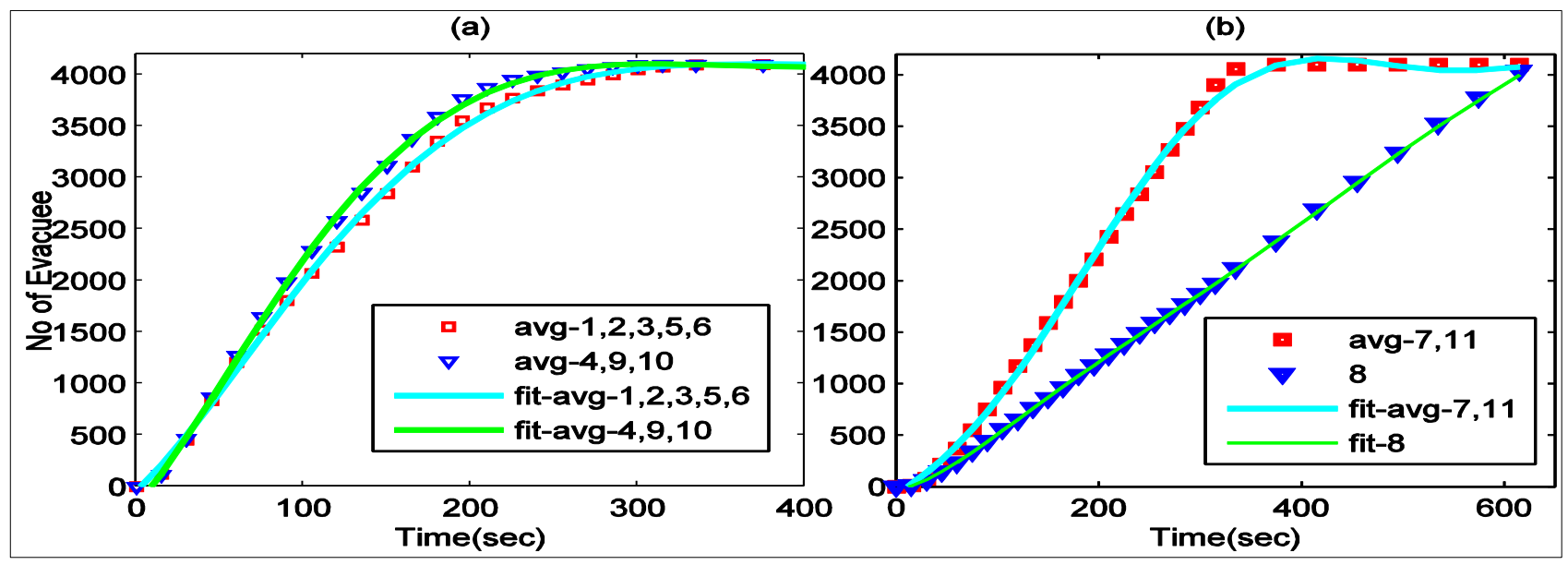

Fig. 11. Evacuation model and average evacuation of nearest test cases

TABLE VI. VALUeS OF $p_{0}, p_{1}, \ldots p_{6}$ FOR DifFERENT SCENARIOS

\begin{tabular}{|c|l|l|l|l|}
\hline Properties & $\begin{array}{l}\text { Avg. of Test Cases } \\
1,2,3,5,6\end{array}$ & $\begin{array}{l}\text { Avg. of Test Cases } \\
4,9,10\end{array}$ & $\begin{array}{l}\text { Avg. of } \\
\text { Test Cases 7,11 }\end{array}$ & Test Case 8 \\
\hline$p_{0}$ & -46.7 & -53.15 & -73.43 & -37.85 \\
\hline$p_{1}$ & 15.05 & 13.7 & 7.034 & 2.053 \\
\hline$p_{2}$ & 0.1252 & 0.2055 & -0.003988 & 0.05817 \\
\hline$p_{3}$ & -0.0009205 & -0.001558 & 0.000415 & -0.0003113 \\
\hline$p_{4}$ & $2.303 \mathrm{e}-006$ & $4.288 \mathrm{e}-006$ & $-1.878 \mathrm{e}-006$ & $8.105 \mathrm{e}-007$ \\
\hline$p_{5}$ & $-2.583 \mathrm{e}-009$ & $-5.333 \mathrm{e}-009$ & $2.919 \mathrm{e}-009$ & $-1.007 \mathrm{e}-009$ \\
\hline$p_{6}$ & $1.099 \mathrm{e}-012$ & $2.515 \mathrm{e}-012$ & $-1.539 \mathrm{e}-012$ & $4.774 \mathrm{e}-013$ \\
\hline RMSE for $\mathrm{f}(\mathrm{t})$ & 44.09 & 36.5 & 64.26 & 8.638 \\
\hline
\end{tabular}

\section{CONCLUSION}

In this work, crowd evacuation for a building-hall is investigated using a popular crowd-simulation software BuildingEXODUS. Eleven evacuation test cases generated using the different experimental setups in the software are simulated. The simulation results are scrutinized to check the effect of various parameters involved in the evacuation performance. It is noted that with higher response time, the response time increases, the evacuation time and response time increase, but the wait time decreases. Evacuation time is small with $50 \%$ attractiveness for all doors (case 4) and with using sign to signal the occupants of the congestion (case 10). It was found that test case 10 has higher wait time than test case 4 . Test case 5 where $5 \%$ occupants use wheelchairs does not differ much on the evacuation characteristics with the normal evacuation (case 1,2). Test case 9 with the extreme behaviour representing emergency evacuation follows the same trend of case 5 . This behaviour of case 5 and 9 is due to the almost constant egress of the people from the confined area through fixed width doors.

Furthermore, simplified evacuation models are developed which are in excellent agreement with the evacuation test results. These models are computationally inexpensive and thus they can immediately compute the evacuation results. 


\section{ACKNOWLEDGEMENT}

The authors would like to thank the Deanship of Scientific Research at Taibah University for their support to conduct this research work.

\section{REFERENCES}

[1] Alginahi, Yasser M., Muhammad N. Kabir, and Ali I. Mohamed. (2013) "Optimization of High-Crowd-Density Facilities Based on Discrete Event Simulation." Malaysian Journal of Computer Science 26: 4.

[2] Wang, J. H., \& Sun, J. H. (2014), "Principal Aspects Regarding to the Emergency Evacuation of Large-scale Crowds: A Brief Review of Literatures Until 2010." Procedia Engineering, 71, 1-6.

[3] Thalmann, D., Musse, S., Kallmann, M., (1999) "Virtual Humans' Behaviour: Individuals, Groups and Crowds," Proc. International Conference on Digital Media Futures, British Computer Society, Bradford, UK, pp. $13-15$.

[4] Helbing D. et al., (2000) "Simulating Dynamical Features of Escape Panic.” Nature, 407, pp. :487-490.

[5] Braun, A. Musse, S., de Oliveira, L., Bodmann, B., (2003) "Modelling Individual Behaviours in Crowd simulation." Proc. of Computer Animation and Social Agents, pp. 143-148.

[6] Bouvier, E., (1997) "From Crowd Simulation to Airbag Deployment: Particle Systems, a New Paradigm of Simulation." J. Electronic Imaging. Vol. 6, No. 1, pp. 94-107.

[7] Musse, S. et al., (1998) "Crowd Modelling in Collaborative Virtual environments." Proc. ACM Symposium on Virtual Reality Software and Technology. pp. 115-123.

[8] Kiyono, Junji, Kenzo Toki, and Fusanori Miura. (2000) "Simulation of evacuation behavior from an underground passageway during an earthquake." In 12th world conference on earthquake engineering. Paper, no. 1800.
[9] Chunmiao, Y., Chang, L., Gang, L., \& Peihong, Z. (2012). "Safety evacuation in building engineering design by using BuildingExodus." Systems Engineering Procedia, 5, 87-92.

[10] Kiyono, J., \& Mori, N. (2004), "Simulation of emergency evacuation behavior during a disaster by Use of elliptic distinct elements." 13th world conference on earthquake engineering, No. 134, pp. 1-6.

[11] Alighadr, S., Fallahi, A., Kiyono, J., Fitrasha, N. R., \& Miyajima, M. (2012) "Emergency Evacuation during a Disaster, Study Case:"Timche Muzaffariyye-Tabriz Bazaar" Iran." Conference proceeding of 15 WCEE, Lisbon.

[12] Onorati, T., Malizia, A., Diaz, P., \& Aedo, I. (2014). "Modeling an ontology on accessible evacuation routes for emergencies." Expert Systems with Applications, 41(16), 7124-7134.

[13] Yang, X., Dong, H., Wang, Q., Chen, Y., \& Hu, X. (2014), “Guided crowd dynamics via modified social force model." Physica A: Statistical Mechanics and its Applications, 411, pp. 63-73.

[14] Abdelghany, A., Abdelghany, K., Mahmassani, H., \& Alhalabi, W. (2014), "Modeling framework for optimal evacuation of large-scale crowded pedestrian facilities." European Journal of Operational Research, 237(3), pp. 1105-1118.

[15] Haron, Fazilah, Yasser M. Alginahi, Muhammad N. Kabir, and Ali I. Mohamed. (2012) "Software Evaluation for Crowd Evacuation Software Evaluation for Crowd Evacuation-Case Study," International Journal on Computer Science Issues. Vol. 9, Issue 6, No. 2.

[16] Nassar, K., \& Bayyoumi, A. (2012), A simulation study of the effect of mosque design on egress times, Proceedings of the Winter Simulation Conference, Berlin, p. 110.

[17] Galea, E. R., Gwynne, S., Lawrence, P. J., Filippidis, L. and Blackshields D., (2011) "buildingEXODUS V5.0 User Guide and Technical Manual," Fire Safety Engineering Group, University of Greenwich, UK. 